\title{
Miocardiopatia dilatada em pacientes com infecção chagásica crônica. Relato de dois casos fatais autóctones do Rio Negro, Estado do Amazonas
}

\author{
Dilated cardiomyopathy in patients with chronic chagasic infection. \\ Report of two fatal autochthonous cases from Rio Negro, \\ State of Amazonas, Brazil \\ Pedro Viñas Albajar', Sônia Velihovetchi Laredo², Mariano Brasil Terrazas ${ }^{2}$ \\ e José Rodrigues Coura ${ }^{1}$
}

\begin{abstract}
Resumo Dois casos fatais de miocardiopatia chagásica crônica dilatada são relatados pela primeira vez em pacientes autóctones do rio Negro, Estado do Amazonas. Ambos os casos, um homem de 45 anos de idade e uma mulher de 44, nasceram e viveram toda a vida na região do Rio Negro, no norte do Estado do Amazonas, tendo sido picados numerosas vezes por triatomineos silvestres em piaçabais da área. Os pacientes que tiveram as reações sorológicas positivas para anticorpos anti-Trypanosoma cruzi (imunofluorescência, ELISA e Wertern blot) desenvolveram nos últimos 5-7 anos um quadro de insuficiência cardíaca progressivo, com aumento global da área cardíaca, bloqueios atrioventricular e de ramo esquerdo e extrassístoles ventriculares, faleceram de insuficiência cardíaca irreversível. Um dos casos em que foi feita a biópsia cardíaca cirúrgica pós-mortem, mostrou na histopatologia, miocardite crônica com infiltrado mononuclear difuso, com áreas de adensamento celular, fibrose, dissociação, fragmentação e hialinização de fibras cardíacas, sugestivo de miocardite chagásica crônica e o PCR in situ foi positivo para Trypanosoma cruzi.
\end{abstract}

Palavras-chaves: Miocardiopatia crônica dilatada. Doença de Chagas. Rio Negro. Amazônia brasileira.

Abstract Two fatal cases of human chronic chagasic cardiomyopathy are reported, for the first time, in autochthonous patients from Rio Negro, Amazonas State. Both cases, (45 year old man and 44 year old woman) who were born and lived their whole lives in the Rio Negro region, in the northern part of the state of Amazonas, reported having been bitten several times by triatomine bugs in their camping huts while gathering piaçava fibers. The patients, who had confirmed positive serology for Trypanosoma cruzi antibodies (indirect immunofluorescence, ELISA and Western blot), developed in the last 5-7 years a progressive cardiac failure, with global enlargement of the heart, atrioventricular and left bundle branch block, ventricular extrasystoles, both dying from irreversible cardiac insufficiency. The histopathology of a post-mortem surgical cardiac biopsy performed in one of the cases showed chronic myocarditis with diffuse mononuclear cell infiltrates, with areas of focal cell accumulation, fibrosis, lytic necrosis of myocardial fibers, suggestive of chronic chagasic myocarditis. An in situ PCR was positive for Trypanosoma cruzi.

Key-words: Dilated chronic cardiomyopathy. Chagas disease. Rio Negro. Brazilian Amazon.

A infecção chagásica na Amazônia brasileira foi sempre considerada como uma enzootia silvestre, desde que Carlos Chagas confirmou, em 1924, como Trypanosoma cruzi parasitos isolados por Aben-Athar em macacos da espécie Saimiri sciureus, do Estado do Pará4. Embora numerosas espécies de animais silvestres tenham sido descritas como reservatórios ${ }^{89}$ e pelo menos 10 das 16 espécies de triatomíneos daquela região tenham sido encontrados infectadas pelo T. cruzi $2^{6713}$, somente em 1969 foram descritos os primeiros casos agudos da infecção humana ${ }^{17} \mathrm{e}$ até 1992 , apenas 38 casos haviam sido publicados na literatura ${ }^{7}$.

\footnotetext{
1. Departamento de Medicina Tropical do Instituto Oswaldo Cruz da Fundação Oswaldo Cruz, Rio de Janeiro, R J. 2. Hospital Getúl io Vargas da Universidade do Amazonas, Manaus, AM.

Apoio financeiro: Conselho Nacional de Desenvolvimento Científico e Tecnológico - CNPq, pela FAPERJ e pelo Programa de Apoio à Pesquisa Estratégica em Saúde (PAPES) da Fiocruz.

Endereço para correspondência: Prof. José Rodrigues Coura. Dept ${ }^{\circ}$ de Medicina Tropical/FIOCRUZ. Av. Brasil 4365, 21045-900 Rio de Janeiro, RJ, Brasil Fax: $55212280-3740$.

e-mail:coura@ioc.fiocruz.br

Recebido em 25/3/2003

Aceito em 12/5/2003
} 
Nos últimos 10 anos, vários casos agudos da doença de Chagas têm sido observados na Amazônia brasileira, a maioria em microepidemias e casos isolados ${ }^{15} 2122$. Entretanto, nenhum estudo sistemático demonstrou claramente a presença de casos crônicos autóctones da doença, embora um inquérito sorológico nacional realizado anteriormente pela SUCAM (hoje Fundação Nacional de Saúde) tenha demonstrado uma prevalência da infecção de $2,4 \%$ no Acre e $1,88 \%$ no Amazonas $^{3}$, com concentração de $6,8 \%$ no município de Barcelos ${ }^{18}$, onde seis casos sorologicamente confirmados $^{10}$ e um caso agudo haviam sido descritos ${ }^{14}$.

A partir de 1991, realizamos vários inquéritos sorológicos e estudos seccionais, incluindo uma avaliação clínica e eletrocardiográfica de pacientes sorologicamente positivos na área urbana de Barcelos ${ }^{5}$ e na área rural deste município e no de Santa Izabel do Rio Negro, em populações ribeirinhas e piaçabais do próprio Rio Negro e dos afluentes Aracá, Demeni,
Curuduri, Padauiri, Preto e Ereré. Estes estudos têm demonstrado uma importante prevalência sorológica da infecção chagásica, positividade do PCR para T. cruzie isolamento desse parasito de casos humanos, de reservatórios silvestres e de vetores (Rodnius brethesi) o que nos levou a considerar a doença de Chagas como emergente na área ${ }^{6}$.

Mais recentemente, temos desenvolvido um estudo de busca ativa de casos autóctones de cardiopatia crônica, encontrando alguns casos suspeitos e dois deles confirmados sorologicamente, com miocardiopatia crônica dilatada grave e desenlace fatal, os quais passamos a descrever.

Normas éticas. O presente estudo seguiu as diretrizes e normas regulamentadoras de pesquisa envolvendo seres humanos, de acordo com a Resolução 196/96 do Conselho Nacional de Saúde, e de protocolo adotado pela Secretaria de Saúde do Amazonas e pelo Hospital Getúlio Vargas da Universidade do Amazonas.

\section{RELATO DOS CASOS}

1 Caso. Paciente de 45 anos de idade, natural do rio Padauiri (divisa entre os municípios de Barcelos e Santa Izabel do Rio Negro), onde morou e trabalhou na extração da piaçaba desde os 15 até os 37 anos de idade, quando se mudou para a capital, Manaus. Nunca viajou para fora do Estado do Amazonas. O paciente referia ter sido picado várias vezes por triatomíneos em piaçabais dos igarapés do rio Padauiri, referindo, também, ter apresentado vários caroços após as picadas no tronco e extremidades. O paciente identificou o vetor em teste de reconhecimento.

O paciente negava hábitos tóxicos e alergias medicamentosas conhecidas. Como antecedentes médicos relevantes referia seis episódios de malária, o último no ano de 1991, negava ter recebido transfusão sanguínea e qualquer antecedente familiar de cardiopatia.

Cinco anos após ter transferido residência para Manaus, aos 42 anos de idade, iniciou quadro subagudo, progressivo, de astenia, dispnéia a esforços médios e distensão abdominal. Um ano depois foi diagnosticado portador de cardiomegalia pela radiografia de tórax (Figura 1) e iniciou tratamento com digoxina, furosemida e Capoten $\AA$. Manteve uma melhora clínica durante um período de 16 meses, depois do qual e apesar do tratamento médico prescrito, agravou-se a sintomatologia apresentando astenia, dispnéia a pequenos esforços, náuseas pós-prandiais e retenção hídrica abdominal com aumento de peso. Foi mantida a medicação mais Aldactone ${ }^{\circledR}$, mas 0 paciente permaneceu com o mesmo quadro clínico. $O$ eletrocardiograma (Figura 2) mostrava um bloqueio AV de $1^{\circ}$ grau, sobrecarga auricular esquerda, bloqueiro de $2^{\circ}$ grau de ramo esquerdo e alteração de repolarização ventricular da parede antero-lateral.

Um mês antes do desenlace fatal, o paciente foi internado no Hospital Universitário Getúlio Vargas, em
Manaus, com ortopnéia, tosse seca, edema de membros inferiores e orientação diagnóstica de insuficiência cardíaca congestiva. Suspeitou-se, pela primeira vez, de cardiopatia chagásica, que uma sorologia realizada na Fundação Hemo-AM de Manaus confirmou. A sorologia foi reconfirmada por imunofluorescência indireta e ELISA no Instituto Oswaldo Cruz e Western blot no Instituto de Medicina Tropical de São Paulo. A ultrassonografia detectou derrame pleural à direita, fígado congesto e ausência de ascite. Os ecocardiogramas (Ecocolordoppler HDI 3.000) evidenciaram uma miocardiopatia dilatada, insuficiência mitral e tricúspide (funcionais) de grau leve e hipertensão arterial pulmonar. O trânsito esofageano e intestinal resultou dentro da normalidade. Finalmente, foi colocado um marcapassos bicameral com indicação de bradicardia ventricular de 36bpm e insuficiência cardíaca congestiva.

O paciente recebeu alta hospitalar, mas duas semanas depois foi reinternado com suspeita de marcapasso não funcionante, pois apresentava uma freqüência cardíaca de $36 \mathrm{bpm}$, ortopnéia e dispnéia aos mínimos esforços. Foi feita prescrição hospitalar com dieta hipossódica, restrição hídrica de $600 \mathrm{ml} / \mathrm{dia}$, Cedilanide®, furosemida, captopril, omeprazol, diazepan, Aldactone ${ }^{\circledR}$, amiodarona, dipirona, metoclopramida, Luftal® e oxigênio. O paciente manteve-se estável dentro da gravidade com pulso de $56 \mathrm{bpm}, \mathrm{PA}$ de $120 / 90 \mathrm{mmHg}$ e afebril. Apresentava palidez muco-cutânea e icterícia leves, ingurgitação jugular e hepatomegalia de $4 \mathrm{~cm}$. Os resultados dos exames durante a internação foram: $1,53 \mathrm{mg} / \mathrm{dl}$ de creatinina, $11,21 \mathrm{mg} / \mathrm{dl}$ de ácido úrico, $110 \mathrm{mg} / \mathrm{dl}$ de uréia, $8.340 / \mathrm{mm}^{3}$ de leucócitos (com $67 \%$ de neutrófilos, $15 \%$ de linfócitos, 7,1\% de monócitos, $6,3 \%$ de eosinófilos e $1,2 \%$ de basófilos), 4,03 milhões $/ \mathrm{mm}^{3}$ de hemácias e $39,5 \%$ de hematócrito. 


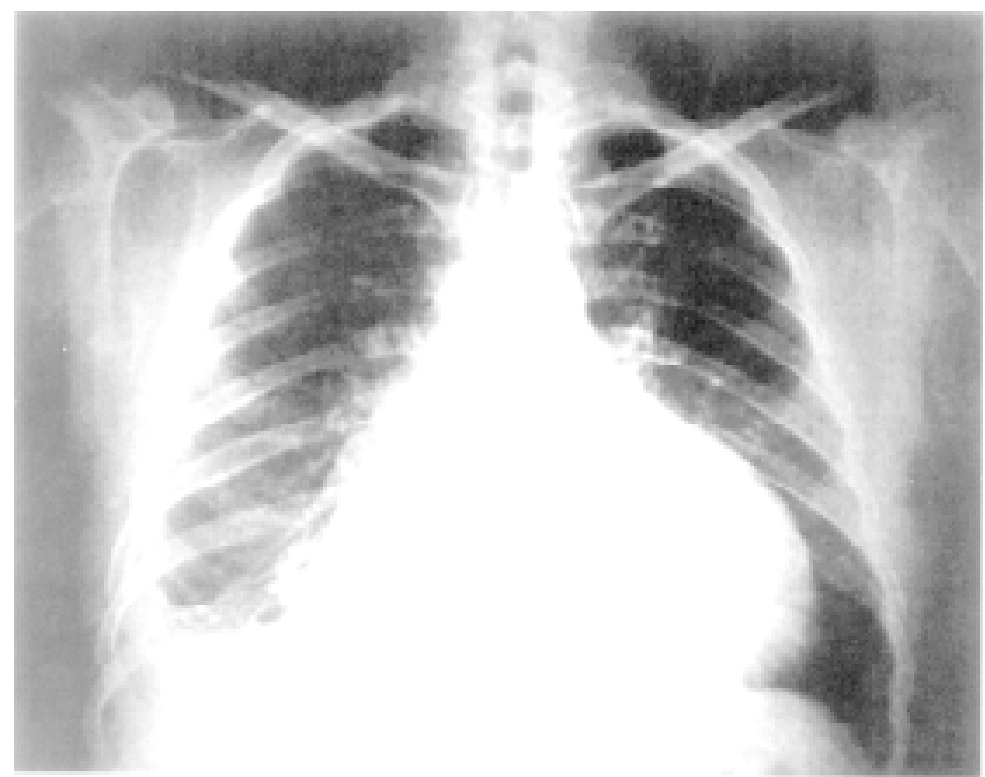

Figura 1 - Radiografia de tórax em AP, mostrando aumento global da área cardíaca e derrame pericárdico à direita.
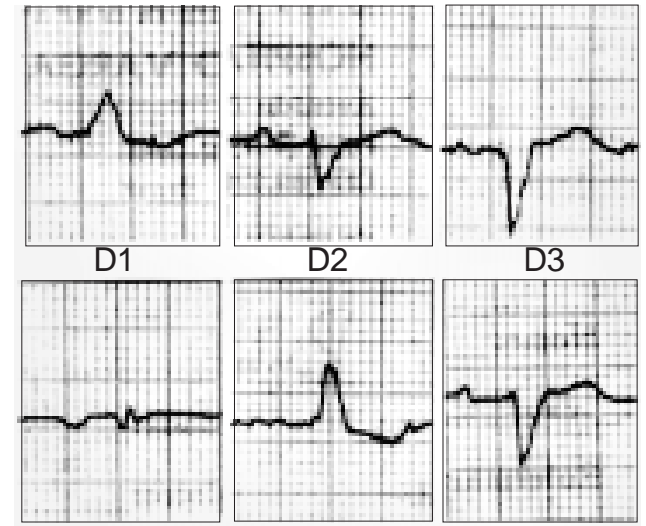

aVR

aVL

aVF

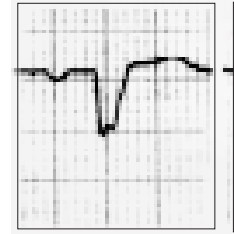

V1

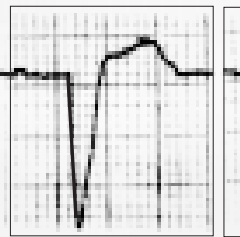

V2

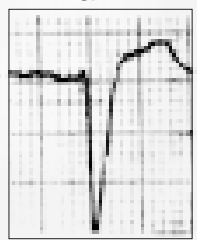

V3

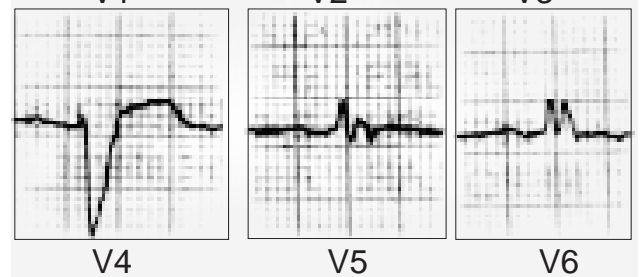

Figura 2 - Eletrocardiograma evidenciando bloqueio A-V de $1^{\circ}$ grau, bloqueio de ramo esquerdo de $3^{\circ}$ grau e alteracỗes de repolarização ventricular de parede antero-lateral. 
$\mathrm{Na}$ madrugada do $22^{\circ}$ dia de internação agravouse o quadro de insuficiência cardíaca congestiva do paciente que não reagiu ao tratamento habitual de choque, vindo a falecer. Não foi realizada a necropsia.

2 Caso. Mulher de 44 anos de idade, nascida no rio Içana, no município de São Gabriel da Cachoeira, onde morou até os 10 anos de idade. Posteriormente foi morar no rio Preto, no município de Santa Izabel do Rio Negro, até que há sete anos veio morar na Comunidade de Piloto, no Rio Negro, próxima à cidade de Barcelos. A paciente nunca viajou fora do Estado do Amazonas.

A paciente trabalhou na extração da piaçaba desde os 10 até os 37 anos de idade, quando deixou o rio Preto em cujos igarapés trabalhou durante 27 anos. Ela identificou o triatomíneo nos testes de reconhecimento, referiu ter sido picada pelo inseto inúmeras vezes e ter apresentado em várias ocasiões caroços após as picadas no tronco e extremidades.

A paciente negava antecedentes médico-cirúrgicos relevantes assim como ter recebido alguma transfusão sanguínea. Como antecedentes familiares, ela referia um irmão que faleceu com inchaço e canseira.
Aos 37 anos de idade deixou o trabalho extrativista porque iniciou sintomatologia com astenia e dispnéia progressiva até aos pequenos esforços, e ortopnéia. Negava edemas, tosse e qualquer tipo de dor.

Aos 42 anos de idade foi consultada pela primeira vez por cardiologista, quem solicitou um ecocardiograma. O ecodopplercardiograma evidenciou uma miocardiopatia dilatada difusa, hipertensão pulmonar, insuficiência mitro-tricuspidea funcional e derrame pericárdico discreto. $O$ resultado do exame sanguíneo foi: 3,3milhões de hemácias, 32\% de hematócrito, 6.000 leucócitos (com 62\% segmentados, $34 \%$ linfócitos, $2 \%$ monócitos, $1 \%$ basófilos). As ultrasonografias de abdome superior e pélvis evidenciaram colecistite alitiásica. Foram realizadas repetidas pesquisas de BAAR com resultado negativo. A paciente retornou à comunidade dela com a prescrição de digoxina, furosemida, Capoten $\AA$ e Aldactone $\AA$. A paciente evoluiu favoravelmente diminuindo a dispnéia (sendo agora só a esforços moderados). Os sinais vitais normalizaram e a paciente continuou tratamento com digoxina, hidroclorotiazida e captopril. Os ECG registraram um ritmo sinusal a $80 \mathrm{bpm}$, com freqüentes extrassístoles, ventriculares, ondas T negativas em V5, V6. (Figura 3).
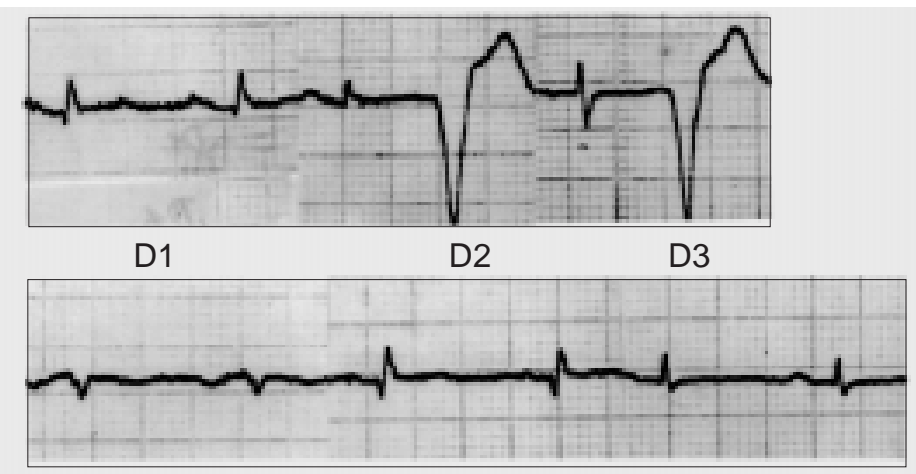

aVR

aVL

$\mathrm{aVF}$
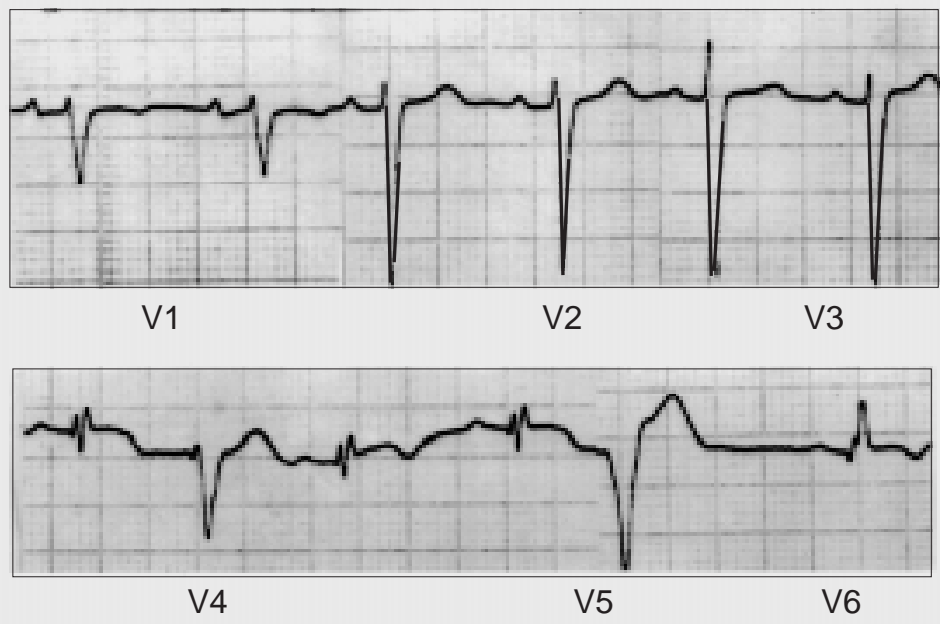

Figura 3 - Eletrocardiograma com freqüentes extrassístoles ventriculares, distúrbio da condução intraventricular do estímulo e ondas T. negativas em V5 e V6. 
Sete dias antes do desenlace fatal, a paciente adoeceu com bronquite aguda, tosse pouco produtiva de catarro branco e anorexia. A paciente não apresentava clínica de insuficiência cardíaca. Foi internada uma semana depois na Unidade Mista de Barcelos para tratar o mencionado quadro de IRA e a prescrição hospitalar manteve o tratamento pregresso acrescentando antibioticoterapia de amplo espectro. Os exames hospitalares mostraram uma leucometria de 11.150 (com $61 \%$ de segmentados, 3\% de bastões, 30\% de linfócitos, $6 \%$ de monócitos, e $0 \%$ de eosinófilos), 3.770 .000 hemácias $/ \mathrm{mm}^{3}, 11,3 \mathrm{gr} / \mathrm{dl}$ de hemoglobina, $34 \%$ de hematócrito e uma VSG de $86 \mathrm{~mm}$ na $1 \stackrel{\text { a }}{\text { hora }}$ e de $102 \mathrm{~mm}$, na segunda. Uma nova pesquisa para BAAR foi negativa. A radiografia de tórax mostrou aumento global da área cardíaca e congestão pulmonar (Figura 4).

$\mathrm{Na}$ madrugada do segundo dia de internação, a paciente iniciou quadro de edema agudo de pulmão por insuficiência cardíaca, com ortopnéia, freqüência respiratória de 45 a 50irpm, pulso de 108bpm, afebril, e com hipotensão grave de até $50 / 30 \mathrm{~mm}$ de $\mathrm{Hg}$.

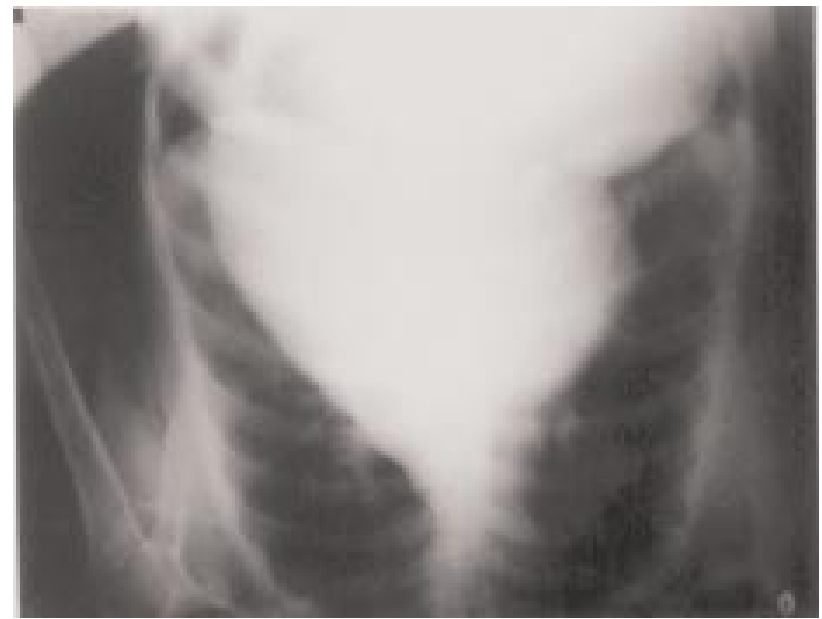

Figura 4 - Radiografia de tórax em AP, mostrando aumento global da área cardíaca e congestão pulmonar.
Não apresentou hepatomegalia nem edema de extremidades. A prescrição hospitalar foi restrição hídrica, Cedilanide $\AA$, furosemida, captopril, cimetidina, aminofilina e oxigênio. A paciente faleceu 12 horas depois de iniciar o quadro agudo de insuficiência cardíaca , com edema pulmonar, não respondendo às manobras e medicação habitual de choque cardiogênico. Foi feita uma biópsia cirúrgica do coração pós-mortem, cuja histopatologia mostrou uma miocardite crônica, com infiltrado mononuclear difuso com áreas de adensamento, fibrose, dissociação e hialinização de fibras cardíacas sugestivo de miocardiopatia chagásica, confirmada por PCR in situ (Figura 5).

Em ambos os pacientes os resultados dos exames sorológicos: imunofluorescência indireta anti T. cruzi, teste ELISA CRA/FRA do fabricante BiomanguinhosFIOCRUZ (leitura visual) e a técnica de Western blot Trypomastigote Excreted-Secreted antigen (TESA) ${ }^{20}$ foram positivos para Trypanosoma cruzi. O PCR no sangue, hemocultura com meio LIT/NNN e xenodiagnóstico direto, foram negativos.

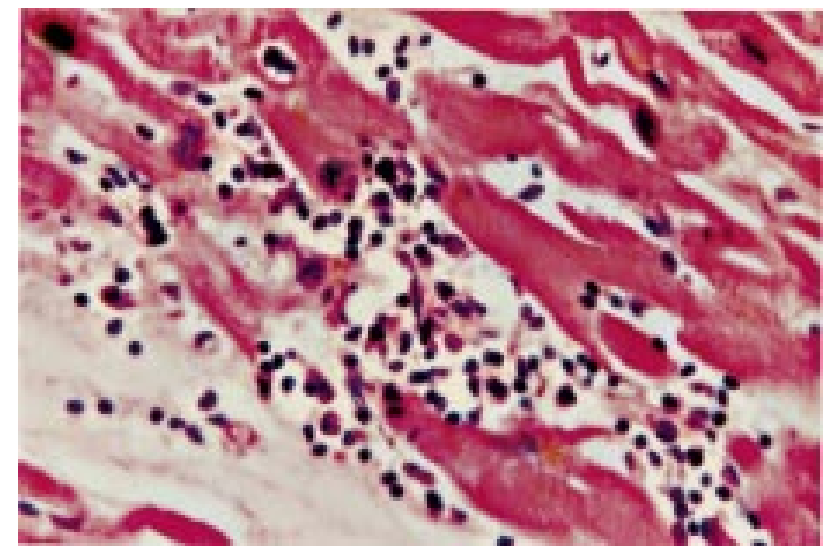

Figura 5 - Histopatologia: fragmentacão e dissociação de fibras miocárdicas, com infiltrado mononuclear predominante e discreta fibrose intersticial.

\section{DISCUSSÃO}

A baixa morbidade da infecção chagásica em nossa área de estudo no Rio Negro foi atribuída em trabalhos anteriores ${ }^{5} 6$ à baixa parasitemia dos casos na fase crônica, demonstrada pelos baixos índices de xenodiagnóstico, hemoculturas e PCR positivos. De fato, em mais de 70 casos sorologicamente confirmados para infecção chagásica tivemos apenas 10 xenodiagnósticos positivos para Trypanosoma cruzi e 16 de PCR, identificando DNA do parasito, o que indica uma baixa parasitemia. Por outro lado, o tipo de parasito circulante na área, classificado como T. cruzi I (silvestre) ou T. cruzi Z3, apresenta baixa patogenicidade para camundongos, atribuindo-se, também, a essa característica a baixa morbidade da infecção na área ${ }^{5}$.
Entretanto, o mesmo não ocorre na fase aguda da doença, onde vários casos apresentam manifestações clínicas exuberantes ${ }^{15} 2122,0$ que contrasta com o reduzido número de casos crônicos sintomáticos na área entre os sorologicamente confirmados.

Infelizmente, não foi possível isolar o parasito por xenodiagnóstico e hemocultura nos casos aqui apresentados, nem o PCR identificou a presença de DNA do parasito no sangue, o que realmente ocorre em um percentual muito baixo em nossa área de trabalho no Rio Negro. Em áreas endêmicas clássicas de doença de Chagas, no Sudeste e Centro-oeste do país, onde circula o T. cruzi II (doméstico), isola-se o parasito por xenodiagnóstico, em média, em 30\% dos 
casos sorologicamente positivos e o PCR pode ser positivo em $50-60 \%$ dos casos. Entretanto, esses percentuais são muito baixos em nossa área de trabalho, entre os casos sorologicamente confirmados. O encontro dos dois casos relatados neste trabalho, deve-se à busca ativa entre vários outros com cardiopatia, que tiveram sorologia negativa para infecção chagásica; estes casos aqui relatados apresentaram sorologia positiva, devendo ser considerados casos excepcionais, até pela forma de apresentação clínica, com manifestações iniciais de comprometimento esquerdo e bloqueio de ramo esquerdo, menos freqüente na cardiopatia chagásica clássica.

A forma crônica cardíaca da doença de Chagas clássica, se caracteriza do ponto de vista histopatológico por uma miocardiopatia inflamatória, com infiltrado mononuclear com áreas de adensamento celular, fibrose, dissociação, fragmentação e hialinização de fibras cardíacas, semelhante a um dos casos apresentados neste trabalho. Alguns casos apresentam focos de reativação subaguda com predominância de linfócitos $\mathrm{CD}^{+}$e fatores citóxicos ${ }^{11} 1619$ importantes na evolução da miocardiopatia, e até formas com intenso parasitismo miocárdio e rápida evolução caracterizada como miocardite chagásica subaguda ${ }^{1}$. Outras forma podem ser mais protraídas com raros focos inflamatórios de lenta evolução, como é o caso da forma indeterminada, naturalmente regulada pela intensidade do parasitismo e pelo tipo de resposta do hospedeiro ${ }^{11}$. Os ninhos de formas amastigotas do T. cruzi podem ser muito raros na miocardiopatia chagásica crônica, podendo atingir em média $30 \%$. Naturalmente, com as técnicas imunoquímicas (imunofluorescência e imunoperoxidase) e de hibridização com PCR in situ, como em um dos casos apresentados neste trabalho, particularmente quando se procura nas áreas inflamatórias, há um grande aumento da positividade ${ }^{1112}$.

Do ponto de vista anátomo-clínico evolutivo, a miocardiopatia chagásica crônica apresenta alguns padrões predominantes, embora não exclusivos: miocardiopatia inflamatória dilatada, com grande aumento da área cardíaca, evoluindo para insuficiência cardíaca ou morte súbita; miocardiopatia inflamatória arritmogênica, com área cardíaca normal ou moderadamente aumentada, comprometimento intenso do sistema de condução e morte súbita e a forma protraída, com lesões residuais, pouco evolutivas. Os casos apresentados neste trabalho enquadram-se no primeiro grupo, com uma característica peculiar - o comprometimento esquerdo predominante, pelo menos na fase inicial da doença. Seria isto uma característica regional ou cepa-específica para o T. cruzi I (silvestre), predominante na área ou apenas uma coincidência em uma área de baixa morbidade para a doença de Chagas? Como não existe um padrão de forma crônica da doença de Chagas na área, estamos aprofundando o estudo clínico, radiológico, eletro e ecocardiográfico de pacientes com sorologia positiva na região, tentando definir melhor a morbidade e as formas clínicas da doença crônica, inclusive com o estudo radiológico e funcional do aparelho digestivo.

\section{AGRADECIMENTOS}

Os autores agradecem a Júlio César Miguel, Laura Cristina Santos e Maria Celeste Dias Spata pelos exames sorológicos e parasitológicos às $\mathrm{Dr}^{\mathrm{a}} \mathrm{s}$ Angela $\mathrm{C}$. V. Junqueira e Eufrosina S. Umezawa pela confirmação sorológica, inclusive pelo TESA-blot à Dra Janice Coelho pelo exame histopatológico e ao Dr. Octávio Fernandes e Nédia N. S. Russel pelo PCR in situ.

\section{REFERÊNCIAS BIBLIOGRÁFICAS}

1. Andrade Z. Patologia da doença de Chagas. In: Brener Z, Andrade Z, Barral Neto M (eds). Trypanosoma cruzi e doença de Chagas, Ed. Guanabara 2a Edição, p. 201-230, 2000.

2. Barret TV, Guerreiro JCH. Os triatomíneos (Hemiptera, Reduviidae) em relação à doença de Chagas na Amazônia. In: Val AL, Figiuolo R, Feldberg E (eds). Bases científicas para estratégia de preservação e desenvolvimento da Amazônia: fatos e perspectivas. Instituto Nacional de Pesquisas da Amazônia. Manaus, p.119-130, 1991

3. Camargo ME, Silva GR, Castilho EA, Silveira AC. Inquérito sorológico da prevalência da infecção chagásica no Brasil, 19751980. Revista do Instituto de Medicina Tropical de São Paulo 26:192-204, 1984

4. Chagas C. Sobre a verificação do Trypanosoma cruzi em macacos do Pará (Chrisotrix sciureus). Nota prévia. Sciencia Médica 2: 75-76, 1924.

5. Coura JR, Junqueira ACV, Boia MN, Fernandes O, Bonfante C, Campos JE, Santos L, Devera R. Chagas disease in the Brazilian Amazon. IV. A new cross-sectional study. Revista do Instituto de Medicina Tropical de São Paulo 44: 159-165, 2002.
6. Coura JR, Junqueira ACV, Fernandes O, Valente SAS, Miles MA. Emerging Chagas disease in Amazonian Brazil. Trends in Parasitology 18: 171-176, 2002.

7. Coura JR, Junqueira ACV, Giordano CM, Funatsu RK. Chagas disease in the Brazilian Amazon. I. A short review. Revista do Instituto de Medicina Tropical de São Paulo 36:363-368, 1994.

8. Deane LM. Animal reservoirs of Trypanosoma cruzi in Brazil. Revista Brasileira de Malariologia 16: 27-48, 1964a.

9. Deane LM. Tripanosomídeos de mamíferos da região Amazônica. III. Hemoscopia e xenodiagnóstico de animais silvestres dos arredores de Belém, Pará. Revista do Instituto de Medicina Tropical de São Paulo 6: 225-232, 1964b.

10. Ferraroni JJ, Melo JAN, Camargo ME. Moléstia de Chagas na Amazônia. Ocorrência de seis casos suspeitos, autóctones, sorologicamente positivos. Acta Amazônica (Manaus) 7:438-440, 1977.

11. Higuchi ML. Human Crronic Cardiomiophaty: Participation of parasite antigens, subsets of lymphocytes, cytokines and 
microvascular abnormalities. Memórias do Instituto Oswaldo Cruz 94 (supl I): 263-267, 1999.

12. Jones EM, Colley DG, Tostes, Lopes ER, Venencab-Jones, Mc Curley TL. Amplification of Trypanosoma cruzi DNA sequence from inflammatory lesions in human chagasic cardiomyopathy. American Journal of Tropical Medicine and Hygiene 48: 348-357, 1993.

13. Lent H, Wygodzinsky P. Revision of triatominaes (Hemíptera, Reduviidae) and their significance as vectors of Chagas' disease. Bulletin of the American Museum of Natural History 163: 125520, 1979.

14. Lima MZMS, Miranda Santo IKF, Souza AAA, Naif RD, Czeco YMT, Miles MA. Caso humano de infecção mista por Trypanosoma cruzi e organismos tipo Trypanosoma rangeli procedente de Barcelos, Rio Negro, Amazonas. In: Resumos do XXI Congresso da Sociedade Brasileira de Medicina Tropical, São Paulo, p. 44, 1985.

15. Pinto AYN, Harada GB, Valente VC, Abud JEA, Gomes FS, Souza GSR, Valente SAS. Acometimento cardíaco em pacientes com doença de Chagas aguda em microepidemia familiar, em Abaetuba, na Amazônia brasileira. Revista da Sociedade Brasileira de Medicina Tropical 34:413-419, 2001.

16. Reis DD, Jones EM, Tostes Jr S, Lopes ER, Gazzinelli G, Colley DG, Mc Curley TL. Characterization of inflammatory infiltrates in chronic chagasic myocardial lesions: presence of tumor necrosis factor+ cells and dominance of granzyme A, CD8+ lymphocytes. American Journal of Tropical Medicine and Hygiene 48: 367-644, 1993.
17. Shaw J, Lainson R, Fraiha H. Considerações sobre a epidemiologia dos primeiros casos autóctones de doença de Chagas registrados em Belém, Pará, Brasil. Revista de Saúde Pública 3:153-157, 1969.

18. Silveira AC, Passos ADC. Altos índices de prevalência sorológica de infecção chagásica em área da Amazônia. Revista da Sociedade Brasileira de Medicina Tropical 19(supl): 45, 1986.

19. Tostes Jr S, Lopes ER, Pereira FEL, Chapadeiro E. Miocardite chagásica humana: estudo quantitativo dos linfócitos CD4 + e dos CD8+ no exudato inflamatório. Revista do Instituto de Medicina Tropical de São Paulo 27:127-134, 1994.

20. Umezawa EF, Nascimento MS, Kesper Jr N, Coura JR, Borges Pereira J, Junqueira ACV, Camargo ME. Immunoblot Assay Using Excreted-Secreted Antigens of Trypanosoma cruzi in serological diagnosis of Congenital, Acute and Chronic Chagas Disease. Journal of Clinical Microbiology 34: 2143-2147, 1996.

21. Valente SAS, Valente VC, Fraiha Neto H. Considerations on the epidemiology and transmission of Chagas disease in the Brazilian Amazon. Memórias do Instituto Oswaldo Cruz 94(supl I): 395398, 1999.

22. Valente SAS, Valente VC, Pinto AYN, Fraiha Neto H. Microepidemia familiar e transmissão oral da doença de Chagas na Amazônia brasileira. Memórias do Instituto Oswaldo Cruz 95(supl II): 69-72, 2000. 